\title{
Synthesis and Characterization of Soluble (Benzene-co-perylene) Copolymer
}

\author{
RAMAN KUMAR SAINI*, DEVENDER SINGH, SHRI BHAGWAN, \\ SONIKA and PRATAP SINGH KADYAN
}

Department of Chemistry, M.D. University, Rohtak-124001, Haryana, India

ramansaini07@gmail.com

Received 23 January 2014 / Accepted 20 February 2014

\begin{abstract}
Soluble copolymer was synthesized from benzene and perylene using Kovcic method. The prepared copolymer was found to be soluble in common organic solvents like chloroform, acetone, NMP etc. Structure, morphology and thermal properties of copolymer were studied by FTIR, Scanning electron microscopy (SEM) and themogravimetric analysis (TGA). Optical properties of the thin films of the copolymer show the UV-Vis spectrum peaks at 294, 429 and $450 \mathrm{~nm}$. The photoluminescence emission was obtained from the copolymer at 505 and $470 \mathrm{~nm}$.
\end{abstract}

Keywords: Soluble copolymer, Photoluminescence (PL), Kovcic method, TGA and thin films

\section{Introduction}

Conducting polymers have attracted attention due to their future applications in large area light-emitting devices or displays, light-emitting diodes, photovoltaic cells, field-effect transistors and photodetectors ${ }^{1-7}$. Polymer light emitting diodes have a good chance to become the main display system in the near future since these diodes have many advantages concerning preparation and operation over the other display systems ${ }^{8}$. Conjugated polymers such as PPP and poly ( $p$-phenylenevinylene) (PPV) have attracted attention as materials for flexible polymer-based light-emitting devices ${ }^{9-13}$. Poly ( $p$-phenylene) (PPP) has several interesting properties. The absence of coupling groups between the phenylene rings makes the polymer less susceptible to degradation by thermal or chemical attack ${ }^{14}$. The outstanding chemical stability of undoped PPP, their ability to resist treatment at very high temperatures and the exceptional mechanical properties found for long substituted poly ( $p$-phenylene) chains, have strong arguments in favor of intensive research development in this area. Despite these extremely promising properties, PPPs consist of very rigid rod-like polymers, so these are insoluble in all organic or mineral solvents, a characteristic that renders the processing of this material very difficult and which probably explains why direct synthetic routes using benzene or its derivatives as the starting reagent do not produce PPPs with high molecular weights and long linear chains. 
To solve this problem many techniques have been used like synthesize a more tractable precursor which can be converted to PPP, substituted benzene used as polymer and add some substituent to aromatic rings or to make a copolymer with suitable molecule. It has been reported that PPP film can be prepared via a soluble precursor polymer ${ }^{15-16}$ or by electrochemical polymerization ${ }^{17-19}$. Vacuum deposition has not been easy to apply to a polymer sample for film preparation. A few reports have appeared about vacuum deposition of PPP for thin film preparation ${ }^{20-21}$. The properties of vacuum deposited PPP films have been reported by Toshima et al. ${ }^{22}$ and Yamamoto et al. ${ }^{23}$. Thus, several approaches have been used to make PPP soluble, including introduction of flexible non-conjugated segments in the polymer backbone $e^{8,24}$ or as side-groups ${ }^{25}$.

In present work we have reported the synthesis and characterization of soluble copolymer of benzene and perylene. The synthesis of copolymer is performed by Kovacic method $^{26}$. The procedure involves the dehydro-coupling of benzene nuclei by catalystoxidant systems, leading to the formation of $\mathrm{C}-\mathrm{C}$ bonds, and provides poly ( $p$-phenylene) in high yield. The reagent is used to carry out the polymerization in a binary system consisting of a Lewis acid (Anhydrous $\left.\mathrm{AlCl}_{3}\right)$ and an oxidant $\left(\mathrm{CuCl}_{2}\right)$.

\section{Experimental}

The copolymer was synthesized by using well known Kovacic method. The synthesis was done on room temperature with benzene ( 2 moles or $156 \mathrm{~g}$ or $178 \mathrm{~mL})$, perylene ( 0.002 mole or $0.50464 \mathrm{~g}$ ) as monomers in 1:1000 ratio and Kovacic mixture (equimolar Anhydrous $\mathrm{AlCl}_{3}$ and anhydrous $\mathrm{CuCl}_{2}$ ) were mixed together to form a homogeneous mixture. Both Cupric Chloride and Aluminum Chloride were made anhydrous by heating at around $120^{\circ} \mathrm{C}$ temperature in a vacuum oven for the 24 hours. Perylene was completely dissolved in benzene then added Kovacic mixture to the solution with constant stirring. With the addition of this mixture intense fumes of $\mathrm{HCl}$ comes out and the color of the mixture turns dark brown. With the addition of Kovacic mixture the viscosity of the reaction mixture started increasing. Temperature for the reaction required was $35-40{ }^{\circ} \mathrm{C}$. The stirring was continued for about 4 hours. The reaction mixture started turning greenish brown with the polymerization. The reaction products were successively washed with $6 \mathrm{~N} \mathrm{HCl}$ and then with distilled water and dried below $100{ }^{\circ} \mathrm{C}$ under vacuum.

\section{Instrumentation}

The prepared copolymer was characterized using Fourier transformation infrared spectroscopy, UV-Vis absorption spectroscopy, thermogravimetric analysis, Scanning Electron Microscope and photoluminescence spectroscopy. UV-Vis spectra was recorded on a Shimadzu UV-2401 spectrophotometer. The thermogravimetric analysis (TGA) was carried out on Mettler Toledo Star System. SEM morphology of the copolymer was taken from LEO-440 Scanning Electron Microscope. The photoluminescence spectrum has been recorded on Horiba Jobin Yvon luminescence spectrometer on films vacuum-deposited on fused silica substrates.

\section{Results and Discussion}

The copolymer of benzene and perylene was prepared by using the Kovacic method. The synthesized copolymer was found to be soluble in the simple organic solvents acetone, NMP and chloroform. The systematic chemical reaction for the preparation of the copolymer shown in the Figure 1. 


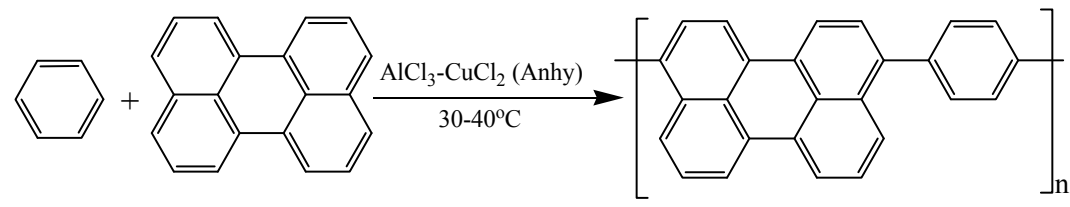

Benzene Perylene Copolymer

Figure 1. Scheme of copolymer

\section{FTIR spectra of copolymer}

The sample of the polymer for FTIR was prepared in freshly cleaned dry $\mathrm{KBr}$ and the pellet of the sample was prepared by the hydraulic press. The recorded FTIR spectrum is shown in Figure 2. The peak at $3027 \mathrm{~cm}^{-1}$ is due to $\mathrm{C}-\mathrm{H}$ stretching of benzene ring in polymer while the peaks at 2923 and $2852 \mathrm{~cm}^{-1}$ were due to $\mathrm{C}-\mathrm{H}$ Stretching vibrations of perylene ring in the polymer. The band occurs in the 2000 to $1700 \mathrm{~cm}^{-1}$ aromatic region. The peaks at 1634 , 1541,1507 and $1480 \mathrm{~cm}^{-1}$ are due to quadrant and semi-circle stretching vibrations of rings. The C-C in plane stretching of aromatic ring is present at 1118 and $1000 \mathrm{~cm}^{-1}$. The peak at $806 \mathrm{~cm}^{-1}$ shows the para substitution of the polymer. The $\mathrm{C}-\mathrm{H}$ out of plane bending present at 765 and $669 \mathrm{~cm}^{-1}$.

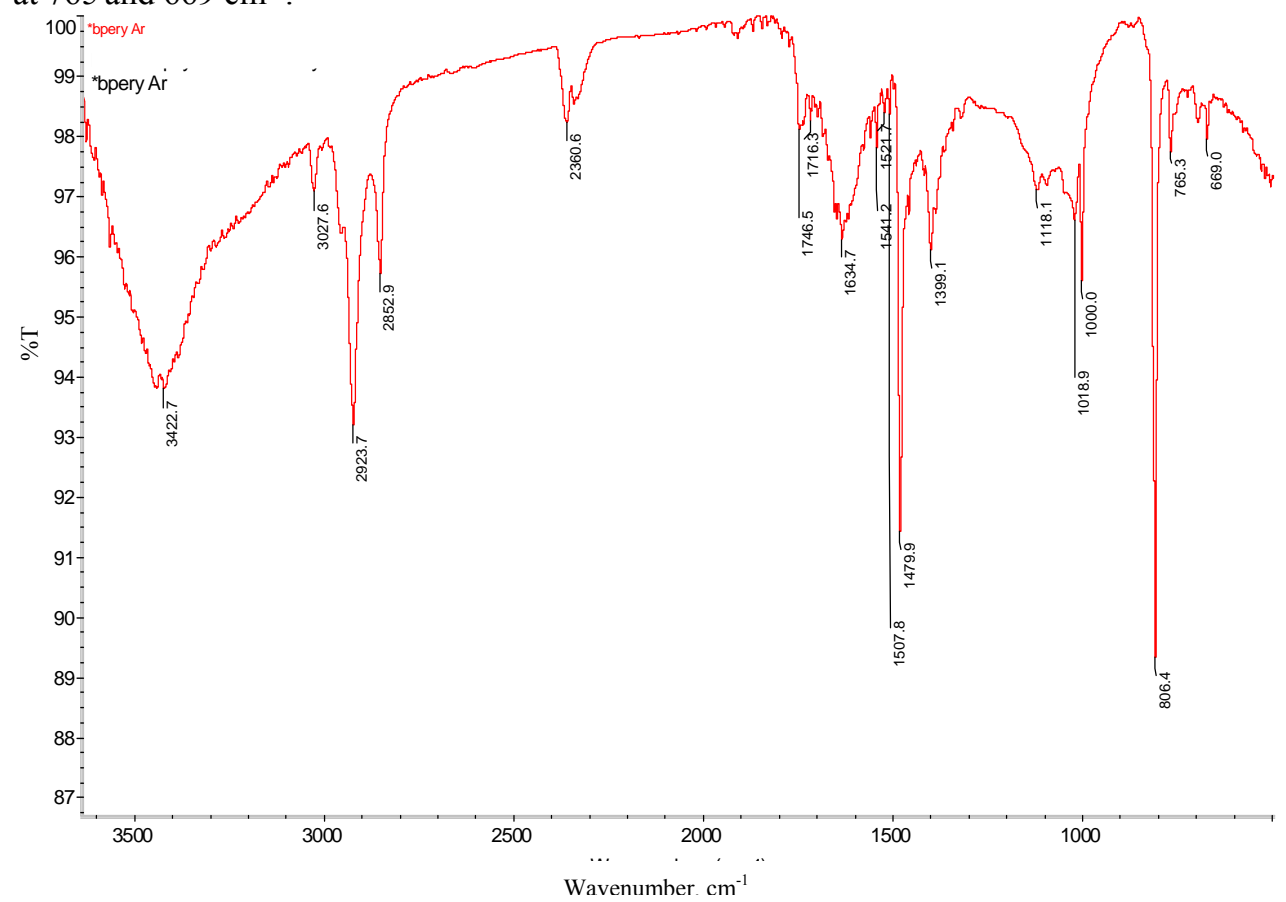

Figure 2. FTIR spectra of copolymer

\section{$U V$-Vis absorption spectra of copolymer}

The UV-Vis absorption spectrum of the copolymer was recorded at room temperature with dilute solutions in chloroform and on glass plate. The copolymer was deposited on the glass substrate for analysis using vacuum deposition machine at below $200{ }^{\circ} \mathrm{C}$ and pressure of $10^{-4}$ to $10^{-5}$ bar. The thickness of the copolymer layer was used $\sim 300 \mathrm{~nm}$. 
The spectra of copolymer on glass plate show peaks at 294,429 and $450 \mathrm{~nm}$ while in of chloroform solution spectra appeared at 270, 286, 429 and $450 \mathrm{~nm}$ as shown in Figure 3. The UV-Vis spectra of copolymer is different correspond to their monomers.

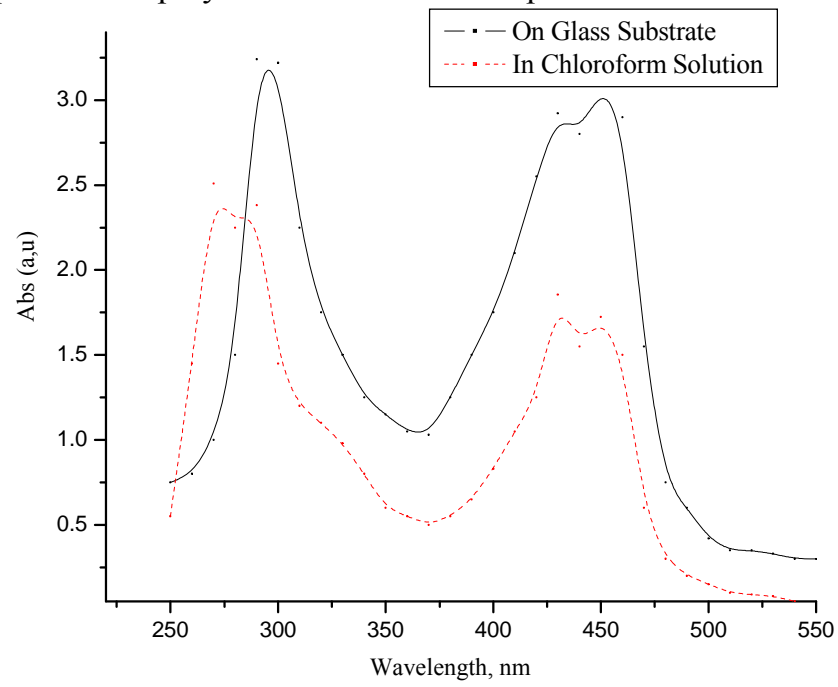

Figure 3. UV-Vis spectra of copolymer

\section{Photoluminescence $(P L)$ spectra of copolymer}

Photoluminescence (PL) spectrum of copolymer was taken as thin film on glass plate and in chloroform solution. Under UV light illumination, copolymer of benzene and perylene show photoluminescence in the visible region. The sample was illuminated with strong $290 \mathrm{~nm}$ radiations from a UV source. Two characteristic peaks at 505 and $470 \mathrm{~nm}$ are observed in both thin film and chloroform as shown in Figure 4. However the strong photoluminescence obtained from the thin films in comparison to the solution form of the prepared copolymeric material.

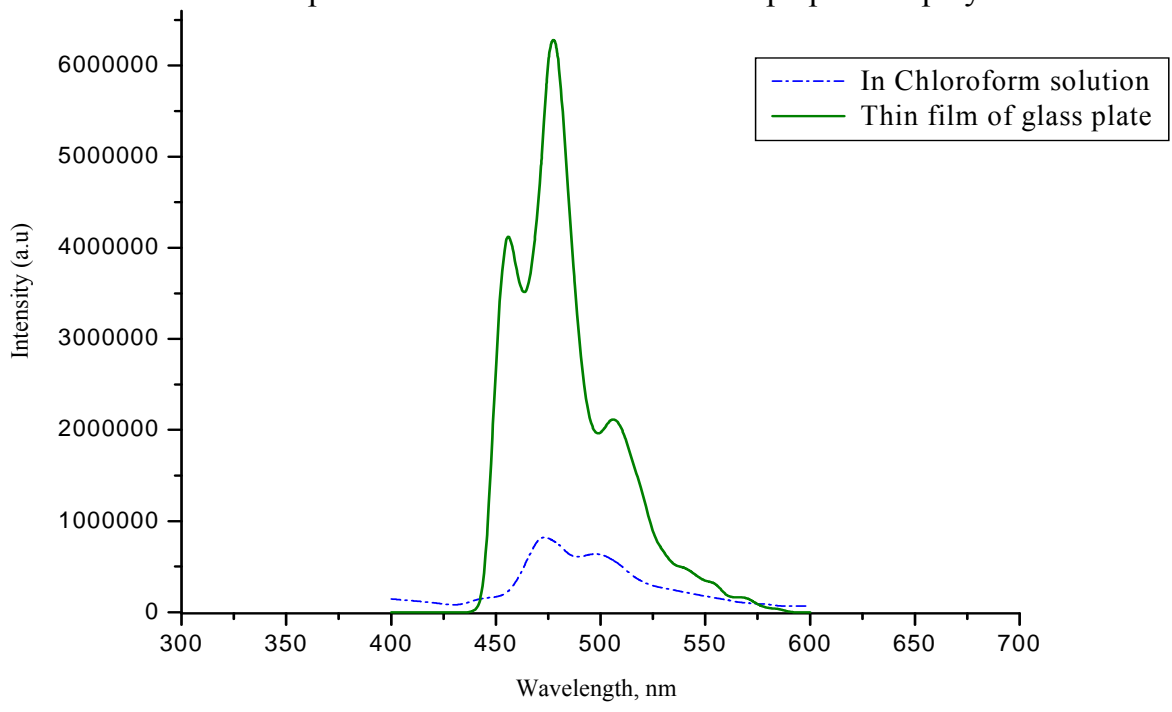

Figure 4. Photoluminescence spectra of the copolymer 


\section{Morphology of the copolymer}

Scanning electron micrographs of the prepared copolymer of are shown in Figure 5. The SEM morphology of the copolymer was taken at different resolution from $1 \mu \mathrm{m}$ to $10 \mu \mathrm{m}$. The copolymer is having spherical shape as the particle accumulated to form round sphere which are clearly shown in SEM micrographs. These spheres of the material may be solid or hollow.
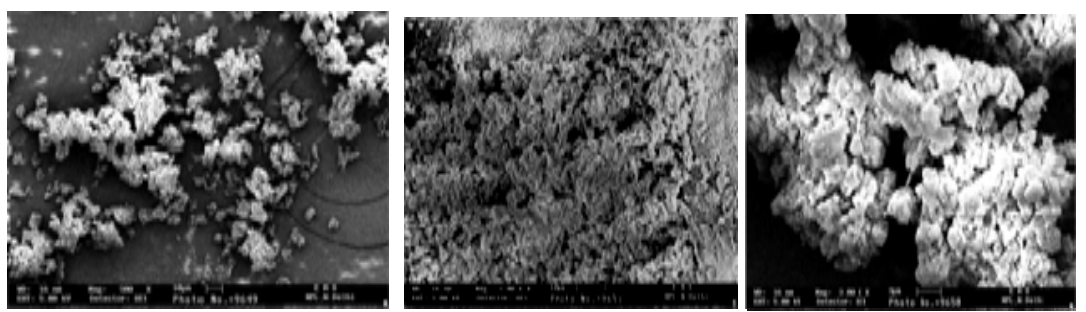

Figure 5. SEM picture for the copolymer

\section{Themogravimetric analysis (TGA) of copolymer}

The copolymer was heated 0 to $800{ }^{\circ} \mathrm{C}$ in TGA furnace with a heating rate of $10{ }^{\circ} \mathrm{C}$ per minute. The TGA furnace was flushed with nitrogen to maintain an inert atmosphere during the thermal decomposition process of copolymer. TGA curve shows slightly decrease in mass 0 to $300{ }^{\circ} \mathrm{C}$ which might be due to moisture content available in the copolymer. Copolymer shows the good thermal and environmental stability. The TGA plot of the material shows loss in mass started at $300{ }^{\circ} \mathrm{C}$ due to the degradation of the polymer chain. The degradation of the polymer continues up to $680^{\circ} \mathrm{C}$. The total lose in the mass of the copolymer was reported up to $22.8498 \%$.

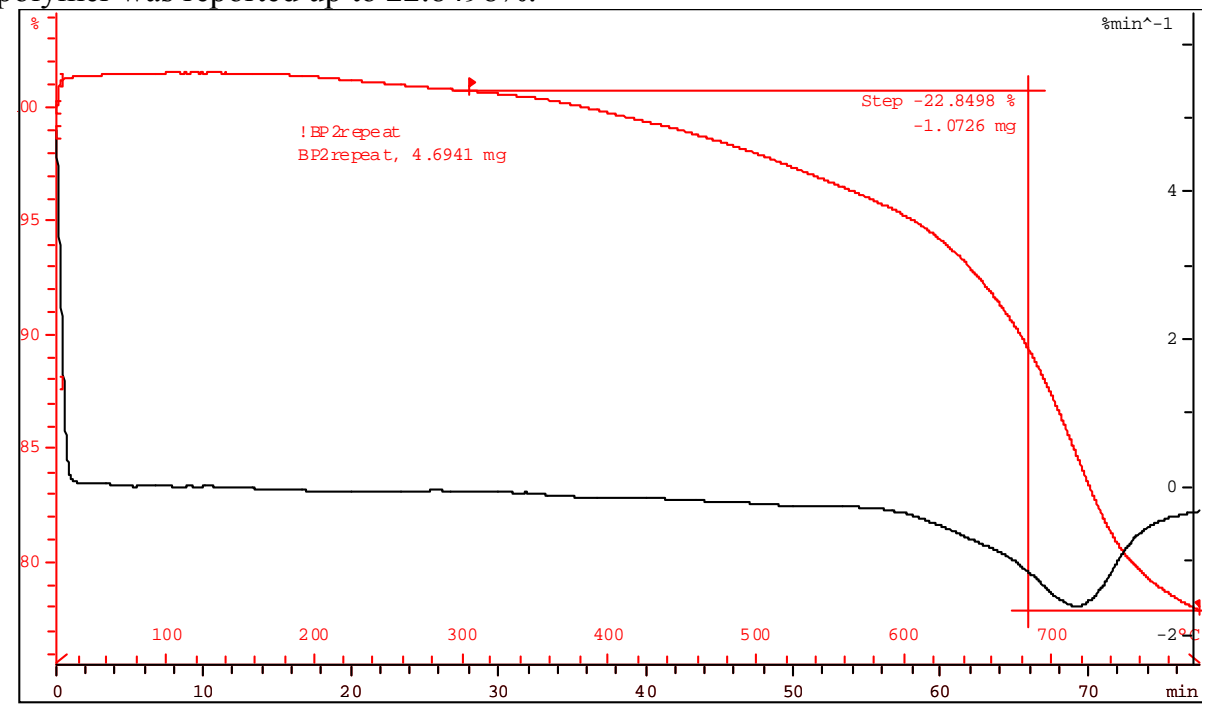

Figure 6. TGA graph of the synthesized soluble copolymer

\section{Conclusion}

Efficiently we had synthesized the soluble copolymer of the benzene and perylene. The prepared copolymer was found to be having good thermal stability up to $300{ }^{\circ} \mathrm{C}$. Copolymer show peaks at 505 and $470 \mathrm{~nm}$ under the strong $290 \mathrm{~nm}$ UV source. The copolymer 
exhibited photoluminescence spectrum in visible region at $(470 \mathrm{~nm})$ so it can be used in various technological display applications. Copolymer of benzene and perylene was found soluble in simple organic solvents such as acetone, chloroform, NMP etc. Hence it can be suitably used for the solution process technique for making OLED devices.

\section{References}

1. Tang C W and Van Slyke S A, Appl Phys Lett., 1987, 51, 913-915; DOI: $10.1063 / 1.98799$

2. Tang C W, Van Slyke S A and Chen C H, J Appl Phys., 1989, 65, 3610- 3616; DOI:10.1063/1.343409

3. Gill R E, Malliaras G G, Wildeman J and Hadziioannou G, Adv Mater., 1994, 6, 132-135; DOI:10.1002/adma.19940060206

4. Conwell E M and Wu M W, Appl Phys Lett., 1997, 70, 1867-1869; DOI:10.1063/1.118716

5. Koehler M, Hümmelgen I A, Appl Phys Lett., 1997, 70, 3254-3256; DOI:10.1063/1.119149

6. $\mathrm{Yu}$ G, Zhang C and Heeger A J, Appl Phys Lett., 1994, 64, 1540-1542; DOI:10.1063/1.111885

7. Bao Z, Lovinger A J and Dodabalapur A, Appl Phys Lett., 1996, 69, 3066-3068; DOI:10.1063/1.116841

8. Kim D Y, Cho H N and Kim C Y, Prog Polym Sci., 2000, 25, 1089-1139; DOI:10.1016/S0079-6700(00)00034-4

9. Grem G, Leditzky G, Ullrich B and Leising G, Adv Mater., 1992, 4(1), 36-37; DOI:10.1002/adma.19920040107

10. Gustafsoon G, Gao Y, Treacy G M, Klavetter F, Colaneri N and Heeger A J, Nature, 1992, 357, 477-479; DOI:10.1038/357477a0

11. Braun D and Heeger A J, Appl Phys Lett., 1991, 58, 1982-1984; DOI:10.1063/1.105039

12. Burroughes J H, Bradley D D C, Brown A R, Marks R N, Mackay K, Friend R H, Burn P L and Holmes A B, Nature, 1990, 347, 539-541; DOI:10.1038/347539a0

13. Uchida M, Ohmori Y, Noguchi T, Ohnishi T and Yoshino K, Japan J Appl Phys., 1993, 32, L921-L924; DOI:10.1143/JJAP.32.L921

14. Holland J R and Richards R W, Polymer, 1995, 36(14), 2773-2780; DOI:10.1016/0032-3861(95)93656-7

15. Jaballah N, Faveb J L, Majdouba M, Chemli M and Saïd A H, Synthetic Metals, 2011, 161(15-16), 1463-1468; DOI:10.1016/j.synthmet.2011.03.031

16. Burgess A N and Nevin A, Polymer, 1992, 33(19), 4141-4144; DOI:10.1016/0032-3861(92)90618-7

17. Aeiyach S and Lacaze P C, J Polymer Science, Part A, 1989, 27(2), 515-526; DOI:10.1002/pola.1989.080270212

18. Mani A and Phani K L N, J Electroanalytical Chem., 2001, 513(2), 126-132; DOI:10.1016/S0022-0728(01)00610-6

19. Kobayashi K, Yang T X, Maruyama K, Shimomura M and Miyauchi S, Synthetic Metals, 1995, 69(1-3), 475-476; DOI:10.1016/0379-6779(94)02532-4

20. Muramatsu Y, Yamamoto T, Hayakawa T and Koinuma H, Appl Surface Sci., 2002, 189(3-4), 319-326; DOI:10.1016/S0169-4332(01)01010-8

21. Yamamoto T, Kanbara T and Mori T, Chem Lett., 1990, 19(7), 1211-1214; DOI:10.1246/cl.1990.1211 
22. Toshima N and Asakura T, Bull Chem Soc Japan, 1993, 66(3), 948-954; DOI:10.1246/bcsj.66.948

23. Yamamoto T, Wakayama H, Fukuda T and Kanbara T, J Phys Chem., 1992, 96(22), 8677-8679; DOI:10.1021/j100201a001

24. Yang C, Scheiber H, List E J W, Jacob J and Mullen K, Macromolecules, 2006, 39(16), 5213-5221; DOI:10.1021/ma061007p

25. Bloom P D and Sheares V V, Macromolecules, 2001, 34(6), 1627-1633; DOI: $10.1021 / \mathrm{ma} 0011791$

26. Kovacic P and Kyriakis A, J Am Chem Soc., 1963, 85(4), 454-458;

DOI:10.1021/ja00887a019 